\title{
METÁFORAS FINISECULARES DEL DECLIVE BIOLÓGICO: DEGENERACIÓN Y REVOLUCIÓN EN EL ANARQUISMO ESPAÑOL (1872-1914)
}

\author{
Álvaro Girón \\ Dpt. of History and Philosophy of Science - University of Cambridge (UK)
}

\begin{abstract}
RESUMEN
La sensación generalizada de un declive masivo en la calidad biológica de las poblaciones europeas se convirtio en un lugar común en la cultura de Fin de Siglo. Estos temores se articularon en gran medida a través del concepto psiquiátrico de degeneración. El lenguaje de la degeneración se asoció pronto a políticas represivas de carácter conservador. A pesar de ello, los anarquistas españoles consideraron que la degeneración era un hecho, aunque establecieron un diagnóstico y una terapia distinta. La decadencia biológica era causada por las condiciones ambientales patógenas creadas por el capitalismo, siendo la única solución realista la revolución. Algunos de ellos no se limitaron a este argumento, postulando el retorno a la naturaleza, la adopción de una forma de vida higiénica, o la difusión de la reforma sexual y el neomalthusianismo.
\end{abstract}

\section{SUMMARY}

The general impression of massive decline in the biological quality of European populations became a common place in Fin-de-Siècle culture. These fears were to a great extent articulated through the psychiatric concept of degeneration. The languaje of degeneration was early on associated with repressive policies of conservative character. In spite of this, Spanish anarchists considered degeneration to be a fact, althought establishing both a different diagnosis and treatment. Biological decadence was caused by the pathogenic environmental conditions created by capitalism, Revolution being the only realistic solution. Some of them did not limit themselves to this argument, postulating a return to nature, the adoption of a hygienic life style, or the promotion of sexual reformed and New Malthusianism.

La impresión de que se estaba produciendo un declive masivo en la calidad biológica de las poblaciones europeas se convirtió en uno de los lugares comunes de la cultura del Fin de Siglo. De hecho, como ha señalado Daniel Pick, el problema de la degeneración se sitúa, entre mediados del XIX y principios del XX, en el centro de la investigación científica y médica. No se trataba ya del tradicional discurso sobre el declive de los pueblos, discutido como si fuera un problema religioso, filosófico o 


\section{ÁLVARO GIRÓN}

ético, sino de la constatación de un hecho empíricamente demostrable desde el punto de vista médico, biológico o de la Antropología Física ${ }^{1}$.

Como es bien sabido, el concepto de degeneración mantuvo siempre cierta ambigüedad. La teoría degeneracionista, elaborada en primera instancia por el médico alienista francés Bénedict-Augustin Morel como una aplicación radical de la doctrina del pecado original al terreno de la enfermedad mental, fue adaptada al contexto general del positivismo evolucionista en los años $1880^{2}$. El degenerado, desde este punto de vista impregnado de evolucionismo, es un enfermo, pero es un enfermo especial que tiende a retroceder a una situación análoga a la del hombre primitivo. De hecho, cuando se utiliza la palabra degeneración durante las últimas décadas del XIX y los primeros años del XX, se está hablando tanto de un espectro patológico imparable que se disemina por las poblaciones europeas, como de un proceso de regresión generalizada que se opone a la evolución perfectiva de la especie.

La propia ambigüedad conceptual facilita que se articule un auténtico lenguaje de la degeneración que impregna la obra de escritores como Zola o Taine ${ }^{3}$, las teorías estéticas de Max Nordau o la Antropología Criminal de Lombroso ${ }^{4}$. De hecho, los temores ante un declive biológico inminente no sólo se relacionaran con el triunfo del decadentismo, o el arte triste, sino con cuestiones de calado político más profundo: los problemas de la post-unificación en Italia, la pretendida repetición patológica de la herencia revolucionaria en Francia, la llamada crisis de la ciudad y los temores de liberales y conservadores ante la naciente sociedad de masas en Gran Bretaña. En España sucede algo análogo. Según Alvarez Uría no se puede comprender el regeneracionismo sin la idea de que había que tomar medidas contra el proceso de degeneración que afectaba a las clases populares ${ }^{5}$.

Los temores de la degeneración no sólo generaron reflexiones de tipo teórico. Impulsaron toda una serie de medidas de orden práctico que fueron desde el campo de la Medicina al Derecho Penal. No se puede entender la génesis de la Medicina So-

1 PICK, D. (1989), Faces of Degeneration. A European Disorder, ca. 1848-ca 1918, Cambridge, p. 20.

${ }^{2}$ Según J. Hochmann, la teoría de la degeneración marca «el cruce de los últimos sobresaltos del creacionismo con la entrada en escena de un evolucionismo más spenceriano que darwinista. Representa también una etapa en un proceso de laicización del pecado original, de transformación del dogma religioso en una mitología pseudo-religiosa de la tara que discurre a lo largo de todo el XIX.» HOCHMANN, J. (1992), «La théorie de la dégénéréscence de B.A. Morel, ses origines et son evolution», en TORT, P. (ed), Darwinisme et societé, París, 401-412. Vid. también: HUERTAS, R. (1985), «Valentin Magnan y la teoría de la degeneración», Revista de la Asociación Española de Neuropsiquiatría, 5, 361-367; HUERTAS, R (1987), Locura y degeneración. Psiquiatría y sociedad en el positivismo francés, Madrid, pp. 50-53.

3 Vid. GREENSLADE, W. (1994), Degeneration, Culture and the Novel: 1880-1940, Cambridge y Nueva York; HUERTAS, R. (1985), «Herencia y degeneración en la obra de E.Zola», Asclepio, 37, 3-37

4 Vid. PESET, J.L y PESET, M. (1975), Lombroso y la escuela positivista italiana, Madrid

5 Alvarez URÍA, F. (1983), Miserables y locos. Medicina mental y orden social en la España del siglo XIX, Barcelona, p. 184. 


\section{METÁFORAS FINISECULARES DEL DECLIVE BIOLÓGICO}

cial, las grandes campañas antialcohólicas, contra la tuberculosis o la sífilis, el mismo origen de la pediatría sin una motivación subyacente clara: la de generar unos instrumentos teóricos y prácticos adecuados que contribuyan a atajar la marea degenerativa, y, si ello es posible, a mejorar la calidad biológica de la especie. Ahora bien, en la medida en que se entendía que la propagación de individuos y grupos humanos degenerados contribuía a la extensión del declive biológico general, se empezaron a elaborar doctrinas, y acciones sociales orientadas por ellas, destinadas a la clasificación, aislamiento o eliminación de este tipo de linajes humanos: la reforma de la penalidad propugnada por la Escuela Positivista del Derecho Italiana (Lombroso, Ferri, Garofalo, etc.), las distintas teorías eugenésicas que dieron cobertura científico-ideológica a la promulgación de leyes de esterilización y leyes de inmigración selectivas, etc.

Aunque el tema de la degeneración, lo que podríamos llamar de manera más precisa degeneracionismo social, está nítidamente asociado a las preocupaciones y ansiedades de las distintas burguesías nacionales, y a un enfoque político-terapeútico que subraya la utilidad de medidas moralizantes cuando no represivas, no es menos cierto que las diversas ramas del socialismo europeo participaron de este clima intelectual. La degeneración biológica se convirtió en un motivo de reflexión para Marx y, en mayor medida, para Engels ${ }^{6}$. La posición mayoritaria, por ejemplo, dentro del partido socialista más poderoso de Europa, el S.P.D. alemán, se basaba en la idea de que el proceso degenerativo (Entartung) era un hecho, pero que se debía imputar a las clases superiores y a las condiciones de vida generadas por el capitalismo ${ }^{7}$. Por otra parte, la idea de que el control de natalidad facilitaría no sólo la libertad sexual, sino que atenuaría el proceso degenerador producido por la sociedad industrial, informaba gran parte de las doctrinas neomalthusianas que se desarrollaron ampliamente en el seno del movimiento anarquista en Francia y España ${ }^{8}$

6 GILMAN, S.L. (1985), «Political Theory and Degeneration: from Left to Right, from Up to Down», en GILMAn, S.L. y Chamberlain, J.E. (eds.), Degeneration. The Dark Side of Progress, Nueva York, 165-198.

7 RUPP-EISENREICH, B. (1992), «Le darwinisme social en Allemagne», en TORT, P. (ed), Darwinisme et societé, París, 169-236

8 RONSIN, F. (1980), La grève des ventres. Propagande néomalthusienne et baise de la natalité française (XIX-XX siècles), Poitiers; NASH, M. (1984), «El neomalthusianismo anarquista y los conocimientos populares sobre el control de natalidad en España», en NASH, M (ed.), Presencia y protagonismo. Aspectos de la historia de la mujer, Barcelona, 307-340; ALVAREZ, R. (1995), «Eugenesia y darwinismo social en el pensamiento anarquista», en HOFFMANN, B., JOAN I TOUS, P. y TIETZ, M. (eds.), $E l$ anarquismo español y sus tradiciones culturales, Frankfurt y Madrid, 29-40). 


\title{
ÁLVARO GIRÓN
}

\section{LA INEVITABLE Y URGENTE SOLUCIÓN: LA REVOLUCIÓN COMO REMEDIO CONTRA LA MAREA DEGENERATIVA.}

Ahondando en el caso español, se puede comprobar como a la altura de los años 1890 gran parte de la élite anarquista española creía que se estaba produciendo un declive masivo en la calidad biológica de la especie. Esta convicción se filtra incluso en la incipiente literatura de corte libertario, como en el caso de un folleto aparecido en Madrid en 1892, en que se describe al protagonista y su familia de una manera que recuerda a los linajes de degenerados zolianos:

\begin{abstract}
«Florencio (...) hallábase expuesto al mismo fin (...) ¿qué término entrevía al final de una carrera, sino una vejez prematura llena de achaques, un cuerpo aniquilado, su esposa enferma y sus herederos raquíticos, inferiores a él, formando el escalón descendente de la raza? Así va toda la especie, de decadencia en decadencia, resbalándose a toda prisa por la inclinación de la miseria y acercándose a todo escape al abismo que se abre espantoso a sus pies»9
\end{abstract}

Es claro que la degeneración esta ahí y es un hecho: ¿cómo atajar este proceso que amenaza a la humanidad civilizada? A este pregunta los anarquistas españoles parecen responder de manera parecida a como lo hace el P.S.O.E. Ricardo Campos ${ }^{10}$ ha mostrado cómo los socialistas españoles veían en la forma en que estaba organizada la sociedad capitalista, la causa última del declive biológico que estaba afectando a la especie. La revolución se convierte para ellos en la medicina privilegiada a la hora de atajar el proceso degenerador.

Se puede decir, que tanto para libertarios como socialistas la palpable degeneración de la especie, su imparable avance exigía la destrucción de una organización social que, en última instancia, era su causa productora. Existía, según ellos, un continuum patológico que iba desde el funcionamiento anormal de la sociedad presente, a su manifestación en la enfermedad general de la especie. Las mismas proporciones del problema exigen la solución revolucionaria. Sólo una acción sobre las causas últimas de la enfermedad de la raza (las bases sobre las que descanse la actual organización social), será verdaderamente eficaz. Esto tiene consecuencias inmediatas de orden práctico y político, en un sentido amplio, cuando se trata de actuar sobre algunas de las que se suponían causas más frecuentes de degeneración: el alcoholismo y la prostitución. Se podría intentar que las mujeres proletarias no se prostituyan, o instruir a los obreros para que no caigan en las redes del alcoholismo. Esto, desde

9 GÓmeZ Humarán, F. (1892), „Destrucción!: Episodio nihilista, Madrid, p. 55.

10 CAMPOS, R. (1992a.), «Herencia biológica y medio social en el discurso antialcohólico del socialismo español (1886-1923)», en HUERTAS, R. y CAMPOS, R. (eds), Medicina social y clase obrera en España, Madrid, 67-91. Para una visión más amplia: CAMPOS, R. (1997), Alcoholismo, medicina y sociedad en España, Madrid. 
luego, no lo excluyeron nunca las distintas ramas del socialismo hispano. Pero resultaba más claro que la auténtica terapia era derribar una organización social que hace que una parte de las proletarias no tengan más remedio que vender su cuerpo, o que propicia que los trabajadores ahoguen sus penas en el alcohol ${ }^{11}$. La degeneración como fenómeno global dictaba sentencia contra la sociedad presente. La Revolución se convertía en la única forma de asegurar la salud del organismo social.

En el caso específico de los anarquistas españoles, la cuestión ya se veía en estos términos aún antes de que se pudiera hablar de la introducción, en un sentido estricto, de las teorías degeneracionistas. Así, en 1872, en el congreso de Zaragoza de la Federación de la Región Española, en un dictamen en que se trataba la licitud del trabajo no doméstico de las mujeres, se intentó desactivar no sólo la idea de que éste pudiera constituir una concurrencia real para los obreros masculinos, sino de que fuera también una potencial fuente de inmoralidad que llevara a la degeneración de la especie. La respuesta era clara: «...la causa de estos males no está en el trabajo de la mujer, sino en el monopolio que ejerce la clase explotadora; transfórmese la propiedad individual en colectiva, y se verá como cambia todo por completo» ${ }^{12}$. La solución, como vemos, es una acción radical, revolucionaria, sobre el medio social.

En el oscuro periodo de clandestinidad de la Internacional en España (18741881), hay un dato significativo que señalar. El principal dirigente de la organización clandestina, Juan García Viñas ${ }^{13}$, lee su tesis Apuntes para el estudio médicohigiénico de la miseria $(1876)^{14}$. Aunque no sea una obra desarrollada a partir de las teorías degeneracionistas ${ }^{15}$. se detectan ya algunas de las constantes del pensamiento

11 Díaz del Moral afirmaba, con respecto al alcoholismo, que constituía para los anarquistas, junto con el tabaco y los juegos de azar, «motivos constantes de sus artículos periodísticos y de las peroratas de sus mítines» DíAZ DEL MORAL, J. (1979), Historia de las agitaciones campesinas andaluzas, Madrid, p. 181. Sin duda, sería muy interesante realizar un estudio comparado sobre las distintas formas de enfocar la cuestión del alcoholismo dentro del movimiento obrero español. Ciertamente, es un tema relevante tanto desde el punto de vista de la historia social (dadas las dimensiones realmente preocupantes del problema para los obreros conscientes), como desde el punto de vista de la historia de la ciencia (ocupaba un lugar central en las teorías degeneracionistas como síntoma y causa a la vez). En la bibliografía sobre la cuestión, destacan sobremanera los recientes trabajos de Ricardo Campos, que ha estudiado la lucha antialcohólica en el socialismo marxista tanto en España, como en el exterior. En espera de la publicación de su tesis doctoral, se pueden consultar: CAMPOS, R. (1992b.), Socialismo marxista e higiene pública, Madrid; CAMPOS, R. (1992a.), 67-91.

12 Citado en LORENZO, A. (1974), El proletariado militante, Madrid, p. 255

13 TERMES, J. (1972), Anarquismo y sindicalismo en España. La primera Internacional, Barcelona, pp. 239 (nota 37) y 268 a 270. Vid. también NETTLAU, M. (1969), La Première Internationale en Espagne (1868-1888), Dordrecht, pp. 329-331.

${ }_{14}$ Utilizamos aquí la reedición contenida en Corbella Corbella, J. y CAlBeT CAMARASA, J.M ${ }^{a}$ (1984), El pensamiento sanitario y laboral de dos médicos anarquistas del siglo XIX, Barcelona.

15 Garcia Viñas no desarrolla un concepto de degeneración claro, entendiendo ésta en el sentido estricto de un proceso patológico multiforme, transmitido hereditariamente y que se agrava progresiva- 


\section{ÁLVARO GIRÓN}

médico-politico en el anarquismo español. Una de ellas, es la preeminencia atribuida a la Higiene sobre el resto de las ramas de la Medicina ${ }^{16}$. Según García Viñas, la ventaja de la Higiene se basa en que ésta tiene un carácter preventivo, $y$, sobre todo, porque al centrarse en la mejora del medio ambiente donde viven los grupos humanos, extiende su radio de acción a las grandes poblaciones. Por otra parte, la idea, repetida hasta la saciedad, de que la Historia ha desviado su curso rectilíneo por la ruptura de la armonía primitiva, tiene también su campo de aplicación en la esfera de la salud ${ }^{17} \mathrm{y}$, como veremos posteriormente, no solo en el caso de García Viñas. Según el médico libertario, es claro que la miseria es la causa productora de «la degradación de la especie» ${ }^{18}$. Pero también es claro que la miseria tiene su origen en la destrucción del estado de naturaleza igualitario, es decir, en aquel momento en que «desapareció el patriarcado en que todos los miembros de la sociedad gozaban en común...» ${ }^{19}$. Desde entonces, el funcionamiento de la sociedad no es fisiológico, como pretende la Economía Política, sino patológico, al producir la enfermedad social que llamamos miseria ${ }^{20}$. En este sentido, se hace necesaria la convergencia de Higiene y Economía Política tomando como principio de ésta convergencia la aceptación de lo que García Viñas llama ley fisiológica de la restitución. En la no restitución del dispendio de fuerzas que representa la actividad nerviosa y muscular realizado en el trabajo humano se encuentra la clave de la conversión de la miseria económica en miseria fisiológica ${ }^{21}$. Dicho de otra manera, la forma en que está organizada la sociedad moderna produce un déficit en el capital orgánico de los individuos. Este tipo de especulaciones tendrá, como veremos, un continuador en la figura de Joan Montseny.

Ya en 1881, cuando los libertarios españoles retoman la actividad legal y sindical, se habla claramente del peligro de degeneración de la especie. En el congreso fundacional de la F.T.R.E celebrado en Barcelona en ese año ${ }^{22}$, los anarquistas se preguntaban si dadas «las condiciones morales y materiales en que vivimos los obreros» no

\footnotetext{
mente. Sin embargo, sí conoce la obra de Morel, ya que lo cita a la hora de hablar de los efectos nefastos del alcoholismo: CORBELLA Y CALBET (1984), pp. 154-155.

16 Se le asigna un papel preponderante frente a otras ramas de la Medicina en la gestión de la vida humana: «La higiene es la encargada de conservar nuestra vida hasta que sobrevenga la muerte natural...» Redacción (1888a.), «Derechos individuales. El derecho a la vida», Tierra y libertad. Quincenario anárquico-comunista, $5,1-2$; p. 1 . Un ejemplo de recomendaciones higiénicas dirigidas al obrero: MÉNDEZ ORDAZ, J. (1882), El amigo del obrero, Sevilla, pp. 25-28.

17 Sobre la cuestión del papel clave de la ruptura de la armonía primitiva: GIRÓN, A. (1996), Evolucionismo y anarquismo en España 1882-1914, Madrid, pp. 77-118.

18 CORBELla y CALBET (1984), pp. 152-153.

19 Corbella y Calbet (1984), p. 164.

20 CORBELla y CALBET (1984), pp. 164-165.

21 CORBella y CALBET (1984), p. 167.

22 Congreso que comenzó a celebrarse el 23 de Septiembre de 1881. Vid: GABRIEL, P. (1979), «El anarquismo en España», en WOODCOCK, G., El anarquismo, Barcelona, 330-388, p. 347; TERMES (1972), p. 275.
} 
se «llegaría a la degeneración física, intelectual y moral de la raza humana.» 23 . Pero es a partir de la segunda mitad de los años 1880 , cuando los libertarios tienen que empezar a hacer frente a planteamientos netamente basados en las teorías degeneracionistas. La recepción y crítica, en el número de Agosto de 1887, de la prestigiosa revista Acracia, de algunos fragmentos de la obra del famoso psiquiatra Charles Féré, Sensación y movimiento ${ }^{24}$, puede ser señalada como un buen punto de partida. En algunos de los fragmentos comentados en Acracia se llegaba a afirmar que «los seres dañosos», es decir, los «criminales y decadentes de toda clase» no debían causar «odio ni cólera», pero la sociedad debía apercibirse contra ellos si no quería «apresurar su propia decadencia» ${ }^{25}$. Dicha aseveración encaja perfectamente en el planteamiento general de Féré. Según él, la propia existencia de los degenerados representaba una amenaza para la propia pervivencia de la sociedad. Socavaban el orden social presente y, dado que dejaban una herencia progresivamente más degenerada, significaban un peligro para el futuro. Dicho de otra forma, el degenerado (individuo aislado y aislable) era por sí mismo causa de degeneración (proceso patológico ubicuo que afectaba al cuerpo social y que se agravaba progresivamente) y, por tanto, debía ser eliminado ${ }^{26}$.

El autor del comentario sobre el libro, probablemente Antoni Pellicer Paraire, está conforme con la idea de Féré de que existía un peligro de decadencia patológica de la especie. Pero es a la hora de buscar causas donde, según el redactor, «el problema pasa de la fisiología a la sociología» y «no nos hallamos de acuerdo con el doctor Féré» ${ }^{27}$ En primer lugar, no se está de acuerdo en quiénes sean los seres realmente «nocivos» o «dañosos»: «...sólo nos habla de decadentes o criminales ¿Por qué el Dr. Féré no cita a las clases privilegiadas sin distinción de ningún género? ${ }^{28} \gg$. Esta línea de descalificación de las clases dominantes será, por cierto, muy frecuente. El patriarca del anarquismo español, Anselmo Lorenzo, afirmaba en 1894 que los vástagos de las clases superiores, que «hacen el amor a desgraciadas hijas del vicio y se afeminan de modo grosero y repugnante» constituían «entes podridos que la higiene

${ }^{23}$ A.I.T.-F.R.E. (1882), Congreso obrero de la región española celebrado en Barcelona, Barcelona, pp. 62-63. En una línea parecida se pronuncia La Federación Igualadina en 1883, destacando la pasividad culpable de la burguesía: Redacción (1883), «Pasado, presente y porvenir de las clases proletarias.», La Federación Igualadina, 4, 1-2; p. 2.

24 No se trata de una reseña de la obra en su conjunto, sino de un comentario crítico sobre algunos fragmentos aparecidos en La Publicidad bajo el epígrafe «Regeneración y Responsabilidad».

${ }^{25} \mathrm{P}$ (1887), «Sensación y movimiento», Acracia , 20, 292-295; p. 292. Cf. FÉRÉ, Ch. (1903), Sensación y movimiento, Madrid, pp. 211-212.

26 Estos puntos de vista alcanzan un pleno desarrollo en su libro de 1888 Dégénérescence et criminalité. Essai physiologique, publicado en París. Para Féré la criminalidad representa un fracaso en el proceso de adaptación. El resto social de inadaptados debía ser eliminado. Vid. PicK (1989), pp. 31-32.

27 P. (1887), p. 292.

28 P. (1887), p. 293. 


\section{ÁLVARO GIRÓN}

debía separar de la sociedad para que no la corrompiesen ${ }^{29}$. Pero es en el análisis más propiamente etiológico donde las diferencias se hacen patentes. El degenerado no es el verdugo-causa, sino la víctima-consecuencia. Por tanto, la eliminación de la parte enferma no garantiza la curación del cuerpo social. Hay que retrotraerse a las causas sociales productoras de la degeneración, es decir, a la diversidad de consecuencias materiales y morales de la explotación de unas clases por otras que impiden establecer una «harmónica vida social» ${ }^{30}$.

De hecho, el peligro de decadencia patológica de la especie se convierte en un formidable instrumento de denuncia de la sociedad presente como causa ambiental productora. Pero ello sólo se podía hacer produciendo una doble inflexión en el discurso habitual del degeneracionismo. Una doble inflexión que supone, en primer lugar, el entroncamiento social de la degeneración y, en segundo lugar, el establecimiento, al menos en el nivel del discurso, de un espacio desde el que el anarquista puede hablar con igual o mayor competencia que el médico. La primera tarea, pues, era convertir el sujeto en predicado, el agente causal en efecto. Para Féré, como para otros muchos, la degeneración - concepto médico-biológico objetivado en una clase de individuos-, era la responsable del proceso degenerativo de la sociedad en un sentido amplio. Como dice Daniel Pick, «la degeneración era vista, cada vez más, por médicos y otros escritores no como la condición social del pobre, sino como una fuerza que se autorreproduce; no como el efecto, sino como la causa del crimen, la miseria y la enfermedad» ${ }^{31}$. Hay que transformar, pues, lo que aparece como un sujeto misterioso y dado que se encarna en el mundo real en una variedad de manifestaciones corporales y conductuales patológicas, en un efecto: en un producto de causas sociales observables, resultado a su vez de una forma contigente de organización social.

La segunda tarea concierne a un cambio de escala, solidario de un establecimiento de campos de competencia. Hay que pasar del organismo individual (territorio del saber donde el médico es el principal experto), al organismo social (campo propio de la sociología, lugar donde el libertario - por el estudio- se siente más autorizado). El médico es, en este sentido, la persona más competente a la hora de hablar de los efectos (la constatación de la propagación creciente de organismos individuales degenerados), pero necesariamente yerra al invadir un campo de investigación que no le es propio (el de las causas sociales de la degeneración). Así, en el artículo citado de Acracia, se lee:

«En ninguna parte de lo que hemos leído, vemos alusión a las verdaderas causas del malestar social; y por esto, con ser admirablemente tratado el asunto como efecto, no lo es tanto como causa. Y así sucede que especialistas muy científicos y observadores, y aun bue-

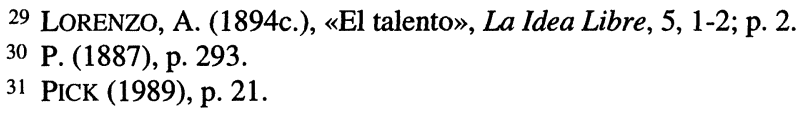




\title{
METÁFORAS FINISECULARES DEL DECLIVE BIOLÓGICO
}

\begin{abstract}
nos pensadores, nos muestran ciertas teorías con una base científica indestructible al parecer, que acaban de ser absurdas al invadir el campo sociológico; como nosotros caeríamos en el ridículo si tratásemos cualquier otro ramo de la ciencia que no hubiésemos estudiado.» 32
\end{abstract}

Este cambio de competencia y de escala, permite a algunos anarquistas criticar la parcialidad de las soluciones propuestas por la medicina burguesa. Anselmo Lorenzo esboza por estos años una crítica acerada contra el higienismo burgués. Es en un artículo de Julio de 1887, en el campo aparentemente más restringido de la sífilis, donde el calado de esa crítica se hace más visible. El punto de partida fue, una vez más, una fuente francesa: los trabajos presentados a la Academia de Medicina de París por el Dr. Fournier, ponente, como se deduce del propio artículo, de la Comisión de profilaxia de la sífilis. Para Fournier, la «sífilis (...) verdadera peste moderna, amenaza la salud pública con un peligro gravísimo y permanente, peligro individual, hereditario y social ${ }^{33}$. Su peligro no derivaba simplemente de que fuera una enfermedad grave y altamente contagiosa, sino de que se la relacionaba con una variedad enorme de dolencias, que finalmente terminaban por alcanzar al propio cerebro. Las consecuencias sociales son de lo más diverso: incapacidad para el trabajo y miseria, separaciones matrimoniales y divorcios, esterilidad, «o lo que es peor aún, degeneración de la raza» ${ }^{34}$. Los remedios propuestos por Fournier están fundamentalmente dirigidos a la represión legal y a la vigilancia médica de la prostitución. Evidentemente no es ésta la línea defendida por Anselmo Lorenzo. La crítica de éste, durísima, se basa en argumentos muy parecidos a los anteriormente comentados: competencia del médico para curar individualmente la sífilis, incapacidad del higienismo burgués para profundizar en las verdaderas causas sociales productoras de la enfermedad y, por tanto, impotencia a la hora de establecer la única profilaxis adecuada, la revolución, a las dimensiones del problema:

«No es esta la manera de atacar un mal cuyas raíces son tan profundas. Mientras los privilegiados usurpen la parte de la riqueza pública que a los desheredados corresponde, y tan inicua usurpación constituya el régimen social de las naciones, habrá necesariamente mujeres cuyo único medio de vida sea la prostitución, hombres que se encenaguen en el vicio y junto con la degradación moral consiguiente se desarrollarán las causas de degeneración de nuestra especie. Los médicos que esto desconocen podrán estar muy versados en el estudio de su especialidad, serán competentes para curar individualmente la sífilis, pero son incapaces de establecer la profilaxia social de tan terrible enfermedad. Conocen una de las fases de la cuestión y sobre ella edifican todo su sistema, pero ignoran completamente las restantes y su sistema es ridículamente inútil. Desengáñense esos higienistas burgueses: todas sus estadísticas,

\footnotetext{
32 P (1887), p. 293.

33 LORENZO, A. (1887), «La sífilis.», Acracia, 19, 274-279; p. 274.

34 Ibidem, p. 275.
} 


\section{ÁLVARO GIRÓN}

todas sus lamentaciones sobre la extensión del mal y todos sus proyectos para su extinción sólo podrán ser eficaces el día que se determinen a entrar en el campo de la revolución social» ${ }^{35}$.

Conviene, sin embargo, que afinemos algo más el análisis. La incapacidad del médico en este caso no se deriva simplemente de su desconocimiento de los grandes temas sociológicos, sino, fundamentalmente, de su condición de burgués. Nos dirigimos a un tópico desde el punto de vista de la retórica política de una gran importancia estratégica: el carácter limitado de las soluciones propuestas por la medicina y ciencia burguesas, es un síntoma, entre otros muchos, del agotamiento de la propia burguesía, y del final de su misión histórica. La situación de injusticia, de miseria social, moral y fisiológica, requiere una solución revolucionaria, pero la burguesía ha dejado de ser un sujeto histórico capaz de llevarla a efecto ${ }^{36}$. La única posibilidad de ir más allá, es la de que actúen aquellos que preservan la capacidad revolucionaria, tanto desde un punto de vista intelectual, como, y ante todo, moral: los trabajadores $^{37}$. De su acción depende no sólo el establecimiento de la justicia, sino el de evitar el avance de la degeneración de la especie. Los trabajadores, en palabras de Lorenzo, llevarán «la acción donde ellos son incapaces de llegar», obteniendo tanto «la emancipación» como la «salud social» ${ }^{38}$.

La impotencia de la burguesía se extiende, con el cambio de siglo, al propio Estado. Lorenzo constata en su folleto de 1900, El trabajo de mujeres y niños ${ }^{39}$ como el reformismo social presenta al «Estado como un salvador dispuesto a dictar leyes protectoras encaminadas a impedir la degeneración de la especie.» Pero el reformismo social o engaña o se equivoca. La acción legal se dirige a la atenuación de los efectos, y no a la actuación sobre las causas. La necesaria y urgente solución es, evidentemente, «abolir la usurpación de la riqueza pública y desvincular la posesión de los medios de producción ${ }^{40}$ ».

35 Ibidem, pp. 278-279.

36 ALVAREZ JUnCO, J. (1991), La ideología política del anarquismo español, Madrid, p. 203.

37 ALVAREZ JUNCO destaca incluso la aparición nada infrecuente de elementos, no ya solamente morales, sino propiamente mesiánicos, en la concepción que del pueblo o de los trabajadores tienen los anarquistas. ALVAREZ JUNCO, J. (1986), « La subcultura anarquista en España: racionalismo y populismo», en V.V.A.A., Culturas populares. Diferencias, divergencias, conflictos, Barcelona, 197-208, p. 206.

38 LORENZO (1887), p. 279. Lo que podríamos llamar crítica del higienismo burgués, no sólo está presente en este artículo. Es bien visible en sendos comentarios bibliográficos, uno de ellos sobre un libro de Jaime Guerra Estapé titulado Higiene de la alimentación de niños (Redacción (1887a.)., «Bibliografía», Acracia, 14, 182-183; p. 183.), y, sobre todo, en el dedicado al de J. Viñeta Bellaserra titulado, La sífilis como hecho social punible, y como una de las causas de la degeneración humana. En el último de ellos se es especialmente crítico: Redacción (1887b.), «Bibliografía», Acracia, 13, 166-167; pp. 166-167.

${ }^{39}$ Aparece publicado junto con otro folleto en: LORENZO, A. (1900), Las Olimpiadas de la Paz y el trabajo de mujeres y niños, Madrid.

40 Ibidem, pp 30-31. 
Pero no sólo es la referencia a la impotencia del Estado lo que aparece como nuevo con el cambio de siglo. Anselmo Lorenzo, en su conferencia de 1903 «Criterio libertario ${ }^{41}$, parece hacer una concesión al clima intelectual del regeneracionismo. La decadencia de España es un hecho, pero se trata del efecto de superficie de un hecho a la vez moral y biológico: la degeneración. Según esto la «degeneración está en la masa de nuestra sangre; sangre de cura, de fraile, de mendigo, de torero, de rufián, de burgués, de explotado» ${ }^{42}$, Este tipo de diagnósticos pesimistas sobre la realidad biológica y moral del pueblo español no será exclusivo de Lorenzo. Cleménce Jacquinet, la primera directora de la Escuela Moderna, también habla de lo inaceptable de la «herencia española», que, según ella, produce «en lo físico, un pueblo desprovisto de fuerzas vivas; en la esfera de la conciencia, miope de inteligencia y de voluntad versátil, antojadiza.... ${ }^{43}$ En otras ocasiones el lenguaje de la degeneración se satura de una clara connotación política. La pasividad de las masas se explica por la degeneración de la raza. Así lo ve Leopoldo Bonafulla, uno de los más activos libetarios del núcleo barcelonés:

\footnotetext{
«Harto sabemos cuales son las consecuencias físicas, morales e intelectuales del trabajo en la sociedad presente. Demasiado lo vemos. La degeneración física de la raza (...) masas sin ideal (...) masa castrada.... ${ }^{44}$.
}

Indirectamente conectado con el tema de la degeneración es el acercamiento de Anselmo Lorenzo - perceptible los años 1910 - al mundo del higienismo y la Medicina Social. En ello puede tener una decisiva influencia la estrecha relación médico-paciente que le unía con el doctor Queraltót ${ }^{45}$. En 1912 ve la luz el folleto El dere-

${ }^{41}$ Utilizamos la edición incluida en LORENZO, A. (1930), Evolución proletaria, Barcelona.

42 LORENZO, A. (1930), p. 234. JACQUINET, C. (1902), p. 41

43 JACQUINET, C. (1902), «La educación rectifica la herencia», Boletín de la Escuela Moderna, 4, $41-44 ;$ p. 41.

44 BONAFUlla, L. (s.f), La familia libre, Barcelona, pp. 109-110.

${ }^{45}$ La presencia de médicos entre los dirigentes libertarios desde los primeros tiempos de la F.R.E. es patente (Gaspar Sentiñón y García Viñas). Pero la relación con practicantes de la medicina que, ocasionalmente, mantuvieron un cierto nivel de compromiso con el movimiento obrero, se intensifica durante los primeros años del XX. Cajal escribe en la Revista Blanca, lo propio hace el Dr. Lluría (sobre Lluría: GONZALEZ DE PABLOS, A. (1992), «Cuestión social, salud y enfermedad en el pensamiento médico socialista y positivista: la obra de Enrique Lluría y Despau (1862-1925)», en HUERTAS, R. y CAMPOS, R. (eds.), Medicina social y clase obrera en España (siglos XIX y XX), Madrid, 427-458). Sin embargo, y a la espera de investigaciones que aclaren la cuestión, da la impresión de que los médicos que dieron ese paso, se mantuvieron más cerca de las posiciones defendidas por el P.S.O.E., que de las defendidas por el movimiento libertario (Lluría - vid. FERNÁNDEZ, E.(1981), Marxismo y positivismo en el socialismo español, Madrid, pp. 284-285- parece ser que estuvo afiliado al partido). Un elemento que de alguna forma facilitó este acercamiento en los años 1910, fue, sin duda, el caso Queraltó (también afiliado -FERNÁNDEZ (1981), p. 284, nota 372-, aunque no sabemos a partir de que fecha, al P.S.O.E.). Parece ser que el 


\section{ÁLVARO GIRÓN}

cho a la salud. El texto procede de una conferencia leída en el Ateneo Barcelonés, dentro de un ciclo organizado, lo cual ya es bastante significativo, por el Institut Médic-Social de Catalunya ${ }^{46}$. En él se postula la necesaria compenetración entre Medicina y Sociología. Según Lorenzo, el médico ha de estudiar la «etiología de la enfermedad», y esto incluye el investigar las «causas productoras de la enfermedad en el medio ambiente». De ahí que afirme que se puede comprender «al sociólogo desconocedor de la medicina, no al médico lego en sociología» ${ }^{47}$. Sin embargo, no quedan muy claras cuáles sean las implicaciones «sociológicas» concretas que el médico habría de deducir de ese conocimiento ${ }^{48}$.

\section{FEDERICO URALES Y EL NATURISMO LIBERTARIO: LA REVOLUCIÓN COMO VUELTA A LA NATURALEZA.}

Otros anarquistas desarrollaron un punto de vista propio sobre la cuestión de la degeneración. Tal es el caso de Joan Montseny. No cabe duda que la crítica a la obra de Lombroso actuó como catalizador ${ }^{49}$, pero el anarquista de Reus no se limitó, ni

doctor Queraltó, según cuenta Manuel Buenacasa, fue condenado por los tribunales de Barcelona por haber denunciado el caso de un desgraciado a quien en un hospital se le desolló la piel de un brazo para eliminar un tatuaje en que se leía la proclama «iViva la anarquía!». Entre los años 1912 y 1913 se organizó una campaña en favor de él, que se convirtió -o al menos esa es la impresión que da el texto de Buenacasa- en una excursión de propaganda libertaria (BUENACASA, M. (1977), El movimiento obrero español 1886-1926, Madrid, pp. 97-98.) Tanto el eco de esa campaña, como los textos de Queraltó (que tratan sobre todo la lucha contra la tuberculosis), tuvieron bastante eco en la prensa libertaria del momento: vid. por ejemplo Redacción (1912b.), «Institut Médic-Social de Catalunya», Tierra y Libertad, 93, 3; p. 3; Redacción (1912c.), «II Congreso español de la tuberculosis celebrado en San Sebastián en Septiembre de 1912», Tierra y Libertad, suplemento al $n^{\circ} 134,1-4$; P.S.A., (1910), «Papel impreso», Acción Libertaria, 1, 4; p. 4; QUINTANILLA, E. (1913), «El caso Queraltó», El Libertario, 29, 3; p. 3.

$46 \mathrm{El}$ Porvenir del Obrero reproduce una reseña favorable de El Liberal de Barcelona. En ella se cargan los tintes pesimistas más allá de lo que lo hacía el propio Lorenzo: Redacción (1912d.), «En el Ateneo Barcelonés. Conferencia de A. Lorenzo», El Porvenir del Obrero, 300, 1; p. 1. Vid. también Tierra y Libertad (1912), números 105 y 106. Sobre la trayectoria del Institut Medic-Social de Catalunya -centrada sobre todo en la organización de conferencias en el Ateneo Barcelonés y en el Ateneo Obrero de la misma ciudad- véase: RODRÍGUEZ OCAÑA, E. (comp.), La constitución de la medicina social como disciplina en España (1882-1923), Madrid, pp. 33-36.

47 Según Lorenzo, esto es evidente por la propia naturaleza de las causas patógenas existentes en el medio social: LORENZO, A. (1930), p. 109.

48 Lorenzo se limita a citar un texto de un médico americano(?), que insiste fundamentalmente en algunos de los remedios habituales propuestos por el higienismo, tales como la educación y la represión de los vicios sociales: LORENZO (1930), p. 110.

49 Sobre el debate entre las posiciones lombrosianas y los anarquistas españoles: GALERA, A. (1988), «Acracia y Antropología Criminal: ciencia y revolución social decimonónica», Asclepio, XL, 247-266; GALERA, A. (1991), Ciencia y delincuencia, Sevilla, pp. 111-140; GALERA, A. (1995), «La 
mucho menos, a la crítica de la obra del psiquiatra italiano, sino que dio a la luz una profusa, y a veces confusa, serie de especulaciones sobre las causas y los remedios de la decadencia biológica del género humano. Por otra parte, es bien perceptible, en la época en que Joan Montseny empieza a escribir bajo el seudónimo de Federico Urales [primera época de La Revista Blanca (1898-1905)], la influencia de la crítica antimodernista, que tendrá en la obra de Max Nordau, Degeneración (1892), una de sus más importantes fuentes en España ${ }^{50}$. Nordau asociaba la tendencia al arte triste, manifestado en la literatura decadente y morbosa de los modernistas, a un estado realmente patológico de los escritores que la practicaban. Pero la literatura decadente no era, tanto para Nordau como para Urales, sino la punta del iceberg de un estado de decadencia biológica generalizado en las sociedades modernas ${ }^{51}$. Por otro lado, la presencia de una fuerte influencia de las teorías higienistas, en su versión sobre todo naturista, es más que evidente en Urales, a la hora de hablar de los posibles remedios.

De hecho, la degeneración de la especie para Urales es, fundamentalmente, una de las consecuencias del divorcio Hombre-Naturaleza, manifestado en este caso en la contradicción existente entre los requerimientos de la actual forma de organización social y las exigencias naturales del organismo individual. La sociedad actual no proporciona las condiciones ambientales apropiadas a un buen cultivo de la especie. Por el contrario, impide o no facilita que se desarrollen las buenas disposiciones inscritas por la Naturaleza en el ser humano ${ }^{52}$. Se trata, sin duda, de un acercamiento a la cuestión que debe mucho a dos presupuestos fuertemente correlacionados en el ideario anarquista: la creencia en la armonía natural y la proclamación como derecho fundamental del derecho a la vida. Según Alvarez Junco, en la teoría anarquista se conectaban los derechos con las necesidades del ser humano. En la naturaleza existe la armonía, no existen «fuerzas contrarias a la expansión de la vida y a la satisfacción de las necesidades de donde se deduce que toda insatisfacción, atrofia o muerte debe atribuirse a la organización antinatural de la sociedad». A toda necesidad se corresponden, o debieran corresponder, «los medios para satisfacerla», y por tanto «surge el derecho a poseer tales medios.» Vivir es el supremo derecho, «y la sociedad tiene la obligación a asegurarnoslo» ${ }^{53}$.

\footnotetext{
antropología criminal frente al anarquismo español», en HOFMANN, B., JOAN Y TOUS, P. y TIETZ, M. (eds.), El anarquismo español y sus tradiciones culturales, Frankfurt y Madrid, 109-120.

50 Sobre la idea de decadencia en la crítica antimodernista y la influencia de Nordau véase LITVAK, L. (1990), Modernismo, anarquismo y fin de siglo, Barcelona, pp. 110-127. Con respecto a la influencia de éste en los círculos libertarios, es significativa la publicación en Acracia de su obra Las mentiras convencionales de nuestra civilización.

51 Sobre este asunto véase: ASCHEIM, S.E. (1993), «Max Nordau, Friedrich Nietzsche and Degeneration», Journal of Contemporary History, 28, 643-657.

52 La cuestión ya se establece en estos términos en 1894: MONTSENY, J. (1894), «Carta a un anarquista», El Corsario, 187, 1-2; p. 2.

53 AlvareZ JunCO (1991), p. 27.
} 


\section{ÁLVARO GIRÓN}

De todo ello se deducen dos conclusiones fundamentales en lo referente a las causas y los remedios de la degeneración. En primer lugar, que la enfermedad y la degeneración son el producto contingente de una sociedad que impide el derecho a la plena satisfacción de las necesidades orgánicas: no hay enfermos naturales ${ }^{54}$. En segundo lugar, que el remedio al estado patológico de la especie, es necesariamente el de que se den las condiciones sociales (ambientales), adecuadas al desarrollo pleno de las exigencias del organismo ${ }^{55}$, es decir, las resultantes del restablecimiento de la armonía entre Hombre y Naturaleza.

Según Urales, es en la ciudad industrial donde supuestamente se hacen más visibles la injusticia y la insalubridad del modo de vida propiciado por la sociedad actual. Por el contrario, «en la vida de la aldea y del campo, donde se manifiesta más libremente la naturaleza», es «donde se producen menos individuos raquíticos» ${ }^{56}$. Nos encontramos, pues, con una versión renovada del viejo tópico del menosprecio de corte y alabanza de aldea. Evidentemente, en esto no estaba sólo Montseny. La gran imagen de la ciudad como centro en el que se propaga y reproduce la degeneración es muy frecuente en el período finisecular ${ }^{57}$. La polarización simbólica entre Naturaleza/campo/salud y Civilización/ciudad/enfermedad la encontramos muy claramente en los anarquistas que se llamaron a si mismos naturistas ${ }^{58}$.

Como es de suponer, ciudad y civilización estaban íntimamente ligados. La idea de que la degeneración era, en cierta manera, el precio a pagar por el avance de la civilización y el progreso estaba muy extendida en toda Europa a final de siglo. Esta sensación generalizada es potenciada, entre otros, por los degeneracionistas franceses, y por Lombroso y sus seguidores ${ }^{59}$. Urales no es ajeno a la gran cuestión: ¿es

\footnotetext{
54 Así lo afirma en 1896 en la Sociología anarquista: «...la naturaleza en sí, sin participación extraña, no produce enfermos.» MONTSENY, J. (1896), Sociología anarquista, La Coruña, p. 81. Tambien: DOCTOR BOUDIN (1898a.), «Ciencia y socialismo», La Revista Blanca, 2, 44-46; p. 45.

55 Subyace a todo esto una visión claramente teleológica de la naturaleza humana que no es exclusiva de Urales. Para los anarquistas españoles, el progreso de la raza humana -también biológico- no es sino el desarrollo de una tendencia preestablecida hacia el bien. La sociedad-ambiente es la que debiera encauzar un desarrollo «tan natural como el de un vegetal...» ALVAREZ JUNCO (1991), p. 96.

56 MONTSENY (1896), p. 59.

57 Esto es especialmente cierto en el caso francés (WEBER, E. (1989), Francia, fin de siglo, Madrid p. 34.). En Inglaterra la preocupación por la ciudad como centro de degeneración también es palpable: vid. PICK (1989), pp. 189-203.

58 Existía un sector en el anarquismo francés llamado naturista que pensaba que la revolución debía de ser fundamentalmente personal, y que concierne sobre todo a la higiene corporal y de la nutrición. Por otra parte, los naturistas estimaban que la civilización era la causa de nuestros sufrimientos, y que en el retorno a la Naturaleza y a una forma de vida primitiva se encontraba la única forma de salvación del género humano (vid. MAITRON, J.(1975), Le mouvemente anarchiste en France. I Des origines à 1914 , París, pp. 379-381.). Este grupo divulga sus ideas en La Revista Blanca: ZiSLY. E. (1902), «Hacia la conquista del estado natural», La Revista Blanca, 102, 167-170.

59 PESET , J.L. (1983) Ciencia y marginación, Barcelona, pp. 98-99.
} 
necesario pagar este precio?. Urales niega en 1900 la fatalidad de la correlación entre civilización y degeneración. Para Urales existe la posibilidad de otro régimen social que combine civilización y salud. Si entendemos civilización como progreso de las luces es claro para Montseny que «con otro régimen social podíamos haber sido sabios sin perder la fortaleza de nuestros primeros padres ${ }^{60}$.

Ya sabemos quién es el responsable; sin embargo, no sabemos cómo actúa: ¿cómo produce la actual forma de organización social degenerados?. Para el Montseny de la Sociología anarquista (1896), la sociedad presente determina de dos maneras su existencia. $\mathrm{O}$ bien obliga a adoptar conductas insanas a los individuos, o bien estos últimos son la víctima de la existencia de condiciones ambientales patógenas por sí mismas. Así, el exceso de trabajo, el vicio resultado de una falsa moral que pervierte la misión de la función sexual, el aire viciado o el alimento escaso y adulterado se convierten en causas de degeneración ${ }^{61}$. Por otra parte, la acción ambiental patógena de la sociedad se extiende a las llamadas enfermedades hereditarias. Esto se explica, según Montseny, porque mientras «dura la gestación el sistema nervioso de la madre hace partícipe al hijo de lo que está pasando en el mundo exterior.» ${ }^{62}$.

Pero es sin duda, en la primera época de La Revista Blanca(1898-1905), donde se hace más claro cuál es el verdadero hilo conductor de la explicación de Montseny. La ya mencionada contradicción básica entre las condiciones de funcionamiento normal del organismo individual y las condiciones artificiales impuestas por el organismo social, se expresa en una serie sucesiva de desequilibrios que se convierten, a su vez, en manifestaciones y causas promotoras de la degeneración de la especie. Estos desequilibrios pueden ser clasificados en dos grupos principales. En primer lugar, los que se relacionan con el agotamiento de las energías corporales y, sobre todo, cerebrales. La sociedad actual, basada en la competencia ilimitada y en la lucha por la existencia que hace que el hombre sea un enemigo del hombre, determina un grado enorme de sobreexcitación nerviosa. Esta sobreexitación, a su vez, se encuentra en la base de una serie de enfermedades nerviosas (neurastenia ${ }^{63}$, histerismo) que culmi-

60 URALES, F. (1900a.), «La evolución de la filosofía en España. Conclusión del tercer capítulo.», La Revista Blanca, 58, 289-295; p. 292.

61 MONTSENY (1896), pp. 82 a 86 y 89.

62 MONTSENY (1896), p. 92.

${ }^{63}$ La neurastenia era la enfermedad de moda en el Fin de Siglo. La palabra, acuñada por el neurólogo norteamericano G. Beard (1880), sirvió para designar toda una clase de desórdenes emocionales e intelectuales que no requerían hospitalización, y que encajaban muy bien en las primeras fases de la degeneración. Se trataba de una enfermedad «elegante», propia de las clases acomodadas y de los profesionales con éxito. También se la asociaba a la sobreexcitación nerviosa propia de la vida urbana. (Vid. CARlson, E.T. (1985), «Medicine and Degeneration: Theory and Praxis», en Chamberlain, J.E. y GILMAN, S.L. (eds.), Degeneration. The Dark Side of Progress, Nueva York, 121-144; pp. 130 y 137; WEBER (1989), pp. 33-34.). Curiosamente la neurastenia también aparece como una fuente de preocupaciones para los anarquistas españoles. Tal es el caso de Mella: «La neurastenia crece, y vivimos una vida 


\section{ÁLVARO GIRÓN}

nan en la locura ${ }^{64}$. El agotamiento puede ser producido, también, por el sobretrabajo a que puede llevar el sistema de salariado: el cuerpo es obligado a gastar más capital orgánico en el trabajo del que recibe en forma de alimento ${ }^{65}$. Los límites naturales del trabajo son señalizados por la fatiga y el dolor que avisan del peligro de lesión orgánica. Pero las exigencias del mercado y los intereses de la burguesía no coinciden con las exigencias que la naturaleza ha inscrito en el organismo del individuo. La sociedad actual produce, en palabras del propio Urales, la falta de armonía entre las entradas y las salidas de capital orgánico:

«...cuando el brazo y la cabeza dicen: no puedo más, el capataz o el gerente contestan, gano el jornal para haceros trabajar, no en relación con vuestras fuerzas, sino en armonía con las exigencias nada equitativas del mercado, con los intereses de la Compañía o del burgués. Claramente se manifiesta el origen genuinamente social de la enfermedad producida por recargo que los hombres sufren»66.

En segundo lugar, la forma de vida moderna, y las falsas reglas de moral fomentan el desequilibrio entre la parte física (animal), y la parte cerebral (supuestamente

artificial de artificios formada. Una crisis nerviosa formidable no se hará esperar. La enfermedad es cierta; la curación dudosa.» RAÚL (1896), «El ocaso de un siglo», La Idea Libre, 96, 1-2; p. 2. Pero los anarquistas dan otra dimensión a la neurastenia (en especial Urales). No es el precio necesario a pagar por el progreso y la vida urbana, sino el efecto perverso de la defectuosa organización de la sociedad presente.

64 Según MONTSENY, parte «muy principal de la locura proviene de desarreglos nerviosos de los que son motivo las dolencias morales, el histerismo, la neurastenia y todas aquellas enfermedades que componen el decálogo de la degeneración de nuestra especie.» Una y otras pueden ser explicadas a través de una sobreexcitación nerviosa causada por las exigencias sociales. La premisa fundamental es la de que exíste un límite pasado el cual no es tolerable mayor excitación: «sea cual fuese el órgano que estuviese en continua excitación, se malpararía a la corta», ya que no «puede trabajar perpetuamente». Así, los «defectos sociales» («ese medio que obliga al hombre a ser un enemigo del hombre») se traducen «en dolores continuos que excitan a los nervios más de lo que puede resistir, no ya los nervios mismos, sino el cerebro, su receptor,» lo que puede llevar a «la locura, es decir, la paralización del cerebro.» DOCTOR BOUDIN (1898b.), «Ciencia y socialismo», La Revista Blanca, 4, 109-111; p. 110.

65 «Así como languidece el cuerpo que se ve obligado a dar más de lo que recibe; así como el organismo que desarrolle mayor suma de fuerza de las que su fuerza permite se atrofia, así también sucumbe todo cerebro sujeto a un trabajo excesivo, siendo la muerte o la locura el fin del proceso iniciado con la falta de armonía entre los estados y las salidas de capital cerebral.» DOCTOR BOUDIN (1899a.), «Ciencia y socialismo», La Revista Blanca, 14, 397-398; p. 397.

66 DOCTOR BOUDIN (1899a.), p. 398. Así, el sistema socioeconómico impide el ejercicio de una libertad básica: cesar de trabajar cuando el organismo avisa del peligro de lesión orgánica: «Si cuando este anunciador de la lesión orgánica avisa del peligro por medio de la fatiga o de gritos de alerta mediante el dolor, tuviera el hombre la libertad interior de cesar en su trabajo (...) o la libertad exterior que se ofrece al que tiene la vida asegurada (...) el ser humano no continuaría produciendo en perjuicio de su vida.» DOCTOR BOUDIN (1899a.), p. 398. 
más humana) en grupos cada vez más amplios de las sociedades europeas ${ }^{67}$. La vida sedentaria lleva a la degeneración de los que solamente cultivan la parte intelectual. Además, Montseny, al asociar la reproducción humana a la parte animal ${ }^{68}$, prevé que el peligro de degeneración de la raza en las sociedades industriales avanzadas, donde se produce el creciente reemplazo de fuerza muscular por fuerza mecánica, sea aún más grave:

\footnotetext{
«El país que da más contingente a la locura es Francia, y Francia es el pueblo intelectual por excelencia. Sigue después Inglaterra, e Inglaterra es una sociedad que ha reemplazado la fuerza muscular por la mecánica, fuerza inventada con enormes gastos de energía cerebral y que viene a convertir al hombre en un ser intelecto, exclusivamente en perjuicio de la procreación y la salud de la especie, cosa que, si no sucede con el tiempo, será debido a que el naturalismo libertario dominará en la tierra mucho antes de que se acaben las energías de la raza humana.»69
}

Pero si hasta ahora hemos hablado de las causas, hora es de que hablemos de los remedios. El remedio por antonomasia a la constatable degeneración de la especie, es, como ya es fácil de deducir, la vuelta a la Naturaleza. Esta idea aparece ya en la Sociología anarquista de 1896, y se repetirá de las más variadas maneras en los años posteriores. La causa última de la degeneración, es sin duda, la caída: la enfermedad general de la especie, es un subproducto más del divorcio Hombre-Naturaleza, que tiene su origen en el principio de los tiempos humanos ${ }^{70}$. En cierta manera se puede decir que Morel y Montseny coinciden en un punto de vista similar: la degeneración no es sino el resultado obligado de la desobediencia, en el primer caso del mandato divino, $y$, en el segundo, de lo prescrito por la Naturaleza en unas leyes que constituyen la manifestación misma de la Justicia. El retorno implica, desde un punto de vista práctico, la satisfacción de las necesidades naturales. Satisfacción que supone, de

${ }^{67}$ Metáfora a su vez del desequilibrio existente entre el sentimiento (animal), que permite la capacidad de gozar (incluyendo esto el sexo), y las capacidades intelectuales (humano-cerebrales). El objetivo antropotécnico sería crear un «hombre capaz para sentir y para pensar, haciendo retroceder a los que sujetos a un trabajo sedentario, hubieran perdido sus condiciones de animal, y haciendo adelantar a los que, trabajando sólo muscularmente, no hubiesen adquirido las de hombre.» MONEY, Ch. (1899), «La igualdad de derechos y el superhombre», La Revista Blanca, 24, 665-666, pp. 665-666.

68 «Si el cerebro es la facultad más elevada del ser racional, si el pensamiento es la nobleza por excelencia, puesto que el hombre ha llegado a él por una serie de evoluciones de cuyos beneficios no participan los demás animales, la reproducción a pesar de su carácter animal y quizás por él, constituye el proceso de nuestra existencia...» DOCTOR BOUDIN (1898c.), «Ciencia y socialismo», La Revista Blanca, 8, 228-229; p. 228.

69 DOCTOR BOUDIN (1899a.), p. 398.

$70 \mathrm{La}$ apelación a los orígenes también la encontramos en Anselmo Lorenzo: «Tenemos una humanidad degenerada, deformada, atrofiada, moralmente anquilosada por causas que radican en tiempos muy anteriores, muy anteriores a la época presente.» LORENZO, A. (1930), p. 188. 


\section{ÁLVARO GIRÓN}

hecho, una conducta que se opone punto por punto a lo prescrito por las normas imperantes en la sociedad presente:

«Pero así como el origen de la enfermedad general que mina nuestra existencia, la existencia de la humanidad entera, viene de lejos y ha ido infiltrándose progresivamente en nuestro organismo al compás de las grandes explotaciones, de las grandes riquezas, así también la humanidad irá emancipándose de las leyes que fomentan y sustentan aquellas grandezas antes dichas y particularmente también volverá al seno natural de donde salió en un momento de travesura infantil, que en la infancia de la humanidad tiene su origen la injusticia social (...) No suponemos que volverá a su estado salvaje al suponer que volverá a su punto de partida, porque el hombre en estado salvaje estaba ya dividido en categorías y por consecuencia en desigualdades; queremos decir que se regirá por leyes naturales y satisfará sus necesidades todas tal como lo irá exigiendo su organismo emancipado de las consecuencias nocivas de una preocupación extremadamente errónea sobre moral, sobre estética, sobre todo lo que hoy es manifestación de saber, de vida, de virtud, etc.» ${ }^{71}$.

¿Pero qué significa esta vuelta a la Naturaleza, aparte de ser fieles a lo prescrito por ella en nuestro organismo?. El auténtico retorno, requiere una revolución destructora. Se trata de «hacer comprender a la humanidad doliente que el remedio de sus males está en la destrucción de esta sociedad, que constituye el virus malsano de la explotación del hombre por el hombre, causa de este mortífero ambiente social». Esta destrucción supondría, ni más ni menos, que en el futuro se llegaría a un punto en que «no habría más ambiente que el que constituyera la región con su topografía, su temperatura, sus productos, sus vientos, sus lluvias, etc» ${ }^{72}$. Como vemos, el objetivo de la revolución es la destrucción de todo «artificio» que se superponga y obstaculice la pureza de la relación entre Hombre y Naturaleza: el ambiente social, per se, contamina esta relación y constituye el principio de toda decadencia ${ }^{73}$.

${ }^{71}$ MONTSENY (1896) p. 90.

72 DOCTOR BOUdIN, (1899b.), «Ciencia y Socialismo.», La Revista Blanca, 27, 71-72; p. 72. Soledad Gustavo asocia la necesidad de la destrucción de la sociedad a la gravedad del estado patológico de ésta: «Cuando el estado morboso de una sociedad es tal que amenaza a llevarla a su desaparición las putrideces y los desequilibrados que en ella vegetan, trabajar para transformarla, - hundirla si la palabra está mejor- es un bien.» GUSTAVO, S. (1898), «La cuestión palpitante», La Revista Blanca, 10, 277-278; p. 277.

73 Urales llega a decir que el «ambiente social es un artificio que se ha formado para impedir que el hombre tomara sus beneficios de la naturaleza, y este ambiente social, causa de la decadencia humana, no es una ley inmutable, es un producto de la perversidad humana, mejor dicho, de la desigualdad humana, cuyo origen se pierde en los ropajes de la civilización cuyo fin se aproxima.» DOCTOR BOUDIN (1899b.), p. 72 . 


\title{
ANTROPOTECNIA: CREAR HOMBRES NUEVOS, CREAR HOMBRES SANOS.
}

Mientras se espera la hora en que suene el clarín revolucionario no hay que permanecer pasivos. Existen medios para atenuar el avance degenerativo. La predica del contacto directo con la Naturaleza ${ }^{74}$, y lo que es más significativo, las recomendaciones insistentes referentes al seguimiento de prácticas higiénicas que aseguren una vida sana ${ }^{75}$, son las recetas preferidas de Montseny. Es más, la medicalización de su discurso es bastante notable, llegando incluso a proponer el manicomio como auténtico modelo a pequeña escala de lo que debiera ser el ambiente de la sociedad futura:

\begin{abstract}
«Luego para combatir la degeneración (...) hace falta establecer un ambiente social adecuado a las condiciones del cuerpo doliente; y siendo como es este el cuerpo social, en lugar de construir un manicomio de reducidas dimensiones, bien ventilado, con ejercicios musculares para los recluidos, recreo, tranquilidad de espíritu, comida abundante, y sin luchas para la existencia; ha de establecerse una sociedad que ofrezca a la especie dolorida todas las condiciones de tranquilidad y de salud que los manicomios modernos ofrecen a los dementes. Sólamente de esta manera las generaciones degeneradas, recobrarán la salud perdida, como sólo con trato amable, aires puros y con una existencia sin excitaciones nerviosas puede recobrar el loco la perdida razón» ${ }^{76}$.
\end{abstract}

Por otra parte, la identificación entre las conductas saludables y lo prescrito por la Naturaleza (una Naturaleza identificada con la Justicia), hace que la salud se considere un valor supremo que, en opinión de Urales, está en radical oposición con la moral vigente $^{77}$. El hombre nuevo de Urales, es ante todo, un hombre sano. Un hombre sano

\footnotetext{
74. «iExisten hombres sanos así del cuerpo como del cerebro!.Vedlos. Son aquellos que viven mas en contacto con la naturaleza;...» MONEY; Ch.(1898), «La naturaleza», La Revista Blanca, 3, 69-70; pp. 69-70.

${ }^{75}$ La creencia en la virtualidad curativa de la vida sana no es exclusiva de Urales. Sebastián Suñé, por ejemplo, cree que «los defectos hereditarios (...) son curables, basándome en que pueden más los elementos de una vida sana, que las deficiencias adquiridas.» SUÑÉ, S. (s.f.), Orientación sociológica, Barcelona, p. 84.

76 URALES, F. (1899), «Literaturas malsanas», La Revista Blanca, 27, 84-87; p. 86. Como vemos, Urales coincide con los alienistas en el papel positivo de la creación de un medio terapeútico alejado del estrés intelectual o emocional del ambiente cotidiano del enfermo (vid. DowBIGGING, I. (1993), La folie héréditaire, París, pp. 177-178). Sin embargo, esta exaltación del manicomio moderno, no es un rasgo generalizable a otros libertarios. Algunos de ellos, como el ruso Pedro Kropotkin o el español Ricardo Mella, destacan lo que Montseny oculta: el internamiento psiquiátrico implica desde el principio privación de libertad. Vid.: KROPOTKIN (1977), Panfletos revolucionarios, Madrid, p. 158; MELLA, R. (1906), «La asistencia pública y la solidaridad», El Porvenir del Obrero, 264, 1; p. 1.

$77 \ll \mathrm{El}$ hombre presente, más perfecto que el pasado y, por consiguiente, más valiente, sencillo y franco ha podido decir que la moral (...) debe ser desdeñada por nociva e hipócrita. Preocupémonos de la salud y no nos preocupemos de la moral» DOCTOR BOUDIN, (1898d.), «Sociología. Moral libre», La Revista Blanca, 6, 163-165; pp. 163-165. La salud es también un valor supremo para Soledad Gustavo:
} 


\section{ÁLVARO GIRÓN}

que, en la sociedad presente, se hace a sí mismo oponiendo a las desfavorables condiciones ambientales un medio propio. Medio propio que es el resultado del seguimiento de una conducta guiada por las normas higiénicas. Un comportamiento que, a su vez, manifiesta una oposición diametral a determinadas formas y espacios de sociabilidad tradicional no saludables:

«En nuestros días es el esfuerzo del individuo, el conocimiento de la higiene, las ganas de vivir y de gozar el que hace a los hombres sanos. Su salud es consciente, es una salud que obtiene robándola con tenacidad del mortífero ambiente que los rodea. Se necesita un carácter que diga a sus amigos y relaciones altas y bajas: "Gracias; no gusto de bebidas espirituosas, porque dañan al organismo. Gracias; no voy al café, a la taberna o al círculo, porque prefiero ir a respirar el aire de la sierra. Gracias; no fumo, porque necesito el dinero para comprarme ropa interior o para hacerme construir un cuarto de baño. Gracias; no os acompaño a la juerga, porque con el dinero que puedo ahorrar he adquirido una casita con jardín donde ejercito mis músculos» 78 .

El objetivo es un objetivo antropotécnico: el naturalismo libertario quiere hombres sanos porque trata de crear caracteres fuertes, dueños de sí mismos y de voluntad poderosa ${ }^{79}$. La precondición biológica de esta autocreación individual y consciente, es la de que los antepasados del individuo en cuestión hayan acumulado una

«La salud es la primera materia de todo lo noble y grande...» GUSTAVo, S. (1903). «El libro de la vida», La Revista Blanca, 113, 513-514; p. 514.

78 Vid: URALES, F. (1901a.), «La evolución de la filosofía en España», La Revista Blanca, 66, 545548; pp. 546-547.

79 «...lo primero que se debe hacer para crear una humanidad feliz, es hombres sanos, fuertes, de voluntad poderosa,...» URALES, F. (1900), «La evolución de la filosofía en España». La Revista Blanca, 52, 97-101; p. 99. Independientemente de las resonancias vitalistas que pueda presentar el vocabulario utilizado por el anarquista de Reus, hay que señalar otra línea de pensamiento que a nuestro parecer ha podido ejercer cierta influencia. Entre los degeneracionistas franceses se produce, a medida que se aproximan a los últimos años del siglo XIX, un cambio de interés desde los estigmas somáticos de la degeneración hacia las manifestaciones psicológicas de ésta. Las llamadas patologías de la voluntad - aquellas que provocan la ausencia de una fuerza consciente que dirija la conducta- empiezan a ocupar el centro de la escena (la obra paradigmática será Les maladies de la volonté de Th. Ribot). Vid. NYE, R.A. (1984), Crime, Madness \& Politics in Modern France, Princeton, N.J., p. 128. La relativa frecuencia de estas patologías se explicaba porque se entendía que la voluntad era una de las últimas adquisiciones en el proceso evolutivo y, por tanto, una de las más susceptibles de perderse. Para un libertario como Urales, la cuestión no podía pasar inadvertida, en tanto que la existencia de una voluntad fuerte era una condición sine qua non de una auténtica libertad, y una barrera efectiva contra cualquier forma de dominación. El individuo sano y fuerte preservará su autonomía «porque el inviduo sano y la humanidad se dirige a la salud y la higiene, es menos sugestionable, esto es, más suyo que el enfermo». Este «hombre nuevo» no es comparable al actual «pasto de todas las enfermedades, singularmente de las peores para su libertad psíquica (...), que matan la libertad interna porque matan el vigor físico.» URALES, F. (1901b.), «La autoridad del talento.», Suplemento de la Revista Blanca, 111, 94; p. 94. 
cantidad suficiente de capital de salud o de energía. ${ }^{80}$ Ahora bien, si de antropotecnia hablamos es lógico aludir aquí a educación. Según Montseny la educación ha de supeditar sus métodos a conseguir el objetivo prioritario de producir hombres sanos. Aquí, se introduce de facto la nueva moralidad basada en la salud. Esta última -que en opinión de Urales es la condición misma de la bondad - se convierte en un objetivo más importante que la sabiduría. La educación, que en esto se opone a la instrucción, ha de asegurar aquello que hace al hombre sano: el contacto con la naturaleza ${ }^{81}$.

Sin embargo, nos encontramos aquí con un poderoso factor limitativo. La acción pedagógica se ve impotente ante la mala materia prima sobre la que tiene que desarrollar su trabajo. Los niños muestran masivamente claros signos de degeneración hereditaria. Aquí deberían converger la pedagogía, un remedio externo, con la sociología, que según Urales sería un remedio interno porque alcanzaría al «niño antes de que sea concebido en las entrañas de la madre puesto que mejora ya el esperma que ha de formarlo» Como ya se puede colegir de lo dicho, Urales parte de un marco, en lo referente a la teoría de la herencia, neolamarckiano. El establecimiento de un sistema social justo llevaría a una especie de herencia de la salud adquirida. Es decir, la mejora del ambiente social, propiciada por la sociología (se podría hablar con más propiedad de ingeniería social), supondría la «mejora de la salud de los que van a ser padres y los prepara para engendrar seres más sanos y fuertes» Sin embargo, es claro que, aún estableciendo una sociedad justa y un ambiente sano, la propia herencia fisiológica no dejaría de transmitir inmediatamente las taras del pasado. Esto es especialmente cierto en un sistema nervioso quebrantado «por largos siglos de recargo y de transtornos morales» Es aquí donde debería intervenir la pedagogía en una segunda fase, haciendo progresar la educación, mejorando con ello, la «salud moral», $\mathrm{y}$, dado que existe una interacción entre psique y soma, mejorando también «el estado del sistema nervioso» Para Urales, por tanto, en la sociedad futura se producirá, por la combinación del establecimiento de un medio social benéfico y una educación

\footnotetext{
80 «...los caracteres fuertes (...), son su propia obra, o, mejor dicho, son la obra que permite elaborar el caudal de energías vitales que heredaron sus antepasados y que continúan manteniéndose incólumes en medio de la degeneración general.» URALES (1901a.), p. 547. Así, en cierta manera, el individuo se convierte en responsable del ahorro de un «capital» que se ha de traspasar a los descendientes: «Sentiría que mis hijos no pudieran decir de su padre lo que yo puedo decir del mío, esto es, que fue un gran capitalista de salud, capital que yo he heredado intacto, y que sospecho no podré legar a mis descendientes...» DOCTOR BOUDIN (1899c.), «Ciencia y socialismo», La Revista Blanca, 22, 622-624, p. 623.

${ }^{81}$ La salud, como hemos dicho, es la precondición de la bondad. Por tanto, esta última no puede ser el resultado del condicionamiento represivo, propio de la instrucción católica, sino del contacto con la Naturaleza: «Este niño - dicen - tiene pensamientos muy ruines, aficiones bajas: es necesario, pues, enviarlo al campo. La raza latina pensaría en darle un preceptor muy religioso o en someter al niño a un régimen represivo, y la raza latina, con esta medida y con otras como éstas, prepara su decadencia. No es ya la religión o la represión lo que hace bueno al hombre: es la Naturaleza con sus atributos». DOCTOR BOUDIN (1899c.), p. 623.
} 


\section{ÁLVARO GIRÓN}

progresivamente perfeccionada, un progreso también continuo en la calidad biológica de la raza. Progreso, que por otra parte, se acelerará porque entre las disposiciones iniciales de la especie está el enamorarse de los individuos más perfectos desde el punto de vista orgánico. Dadas estas condiciones, se puede asegurar que en unas «pocas generaciones» la especie humana llegaría a ser «una raza fuerte, una raza bella y una raza buena» ${ }^{82}$.

Pero si de antropotecnia se trata, es claro que todo lo que tenga que ver con la reproducción humana tiene un papel tremendamente relevante. El amor, en no pocas ocasiones, era mencionado como uno de los ingredientes indispensables a la hora de producir una descendencia de buena calidad. Era evidente, por otra parte, que en opinión de un buen número de anarquistas españoles, las condiciones socioeconómicas, la existencia de normas sociales represivas y de una moral falsa, determinaban que la reproducción se convirtiera en algo independiente del amor. Ya en 1891, Josep Llunas, comentaba que el matrimonio era una mera operación de cálculo en la que pocas veces intervenía la «espontaneidad del amor». La familia se constituía, pues, sobre bases antinaturales, y por tanto, la descendencia forzosamente debía de ser defectuosa ${ }^{83}$. Montseny y Soledad Gustavo, verán, por su parte, en las restricciones legales y «morales» al libre desarrollo de las pasiones y de los sentimientos, una de las causas de la decadencia de la raza. No puede surgir un fruto «robusto» de una unión forzada en la que el amor, o no ha existido nunca, o ya ha dejado de existir ${ }^{84}$. La regeneración como consecuencia, requiere la eliminación de todas las trabas, es

82 URALES, F. (1902), «La evolución de la filosofía en España», La Revista Blanca. 94, 673-677; p. 674. La idea de una contribución activa y personal a la mejora biológica de la raza no es exclusiva de Urales. Josep Prat en 1894 pensaba que la «selección natural» tenía como fin «perpetuar la raza» y «mejorar la humanidad». Por tanto, había que ponerse en disposición de ser seleccionado, es decir, de adquirir cierta superioridad, de tal manera que podamos «transmitir a las generaciones futuras gérmenes sanos.» PRAT, J. (1894), «La fuente de la vida», La Idea Libre, 18, 1-2; pp. 1-2.

${ }^{83}$ LLUNAS, J. (1891), Qüestions socials, Barcelona. pp. 65 y 67-68.

84 Soledad Gustavo lo afirma con rotundidad: «Hoy el hombre ama a todo el mundo más que a la madre de sus hijos y la mujer ama a todos los hombres más que al hombre propio ¿Cómo no han de producirse deformidades? ¿Cómo el fruto de esta unión ha de ser bello y ha de estar sano?.» GUSTAVo, S. (1899), «La Sociedad Futura», La Revista Blanca, 22, 609-611; p. 609. Para Montseny las formas actuales de reglamentación de las relaciones sexuales, eran las responsables de la violación de una ley de la Naturaleza: la conexión entre amor y reproducción. Según él, dicha conexión existía en todo el mundo animal: «Es tan indispensable el amor para la reproducción que no hay animal que deje de sentirlo. Sólo al hombre le estaba reservado reproducirse sin aquella atracción y simpatía inherente a la unión de los seres de diferente sexo...» MONTSENY (1896), p. 96. Bonafulla, por su parte, afirma que «la institución del matrimonio resulta nociva al interés de los padres y de los hijos, en tanto que viola la ley de la selección natural...» BONAFULLA (s.f), La familia libre, p. 59. 
decir, la generalización de la práctica del amor libre, que aseguraría en todo momento las condiciones afectivas adecuadas para una buena reproducción ${ }^{85}$.

Cosa distinta es cuando pasamos de las condiciones en que se desarrolla la reproducción a la cuestión más espinosa de quién debe o no reproducirse. Enrique Vives, en 1896, afirmaba que la «raza periclita» a causa del barbarismo de unas instituciones sociales que llevan a una auténtica «selección al revés.» Dichas instituciones, según Vives, hacen que se perpetúen individuos que no reúnen las condiciones de calidad biológica mínimas mientras hace que los organismos más aptos desaparezcan. Tal es el caso de la maquinaria de guerra que se lleva «a lo más fresco y vigoroso de la generación joven», de tal manera que se deja «la noble función de perpetuar la raza, a los débiles y contrahechos que se les ha dispensado de ser soldados», o a aquellos «que han vuelto del servicio en estado deplorable.» El industrialismo moderno según Vives -en una línea que ya hemos visto en Urales-, exige del individuo «un esfuerzo exagerado» convirtiéndolo en un ser «inepto para la reproducción en el amplio sentido de la palabra.» Finalmente, «en el charco cenagoso de la prostitución se hunde lo más hermoso del sexo femenino», desempeñando las funciones de reproducción «mujeres de escasa belleza», con lo que el «fruto no será probablemente un dechado de hermosura.» La solución, para Vives, pasa, una vez más, por la acción revolucionaria ${ }^{86}$.

\footnotetext{
${ }^{85}$ Según Urales «con el amor libre el fruto de la unión de los cuerpos sería más inteligente y más bello. ¿Por qué?. Porque sería el verdadero fruto del amor.» De hecho, en la sociedad presente los hijos ilegítimos, resultado de una relación espontánea, son mas «geniales» y «hermosos» (Montseny se apoya aquí en lo que Ribot llama «estados accidentales y transitorios en el acto de generación»: RIBOT, Th. (1902), «La ley de herencia directa o inmediata», La Revista Blanca, 102, 178-182; p. 179). Por tanto, el establecimiento del amor libre, y la supresión del matrimonio se convierten en una necesidad si se quiere evitar la propagación de los degenerados» URALES, F. (1903), «Anarquismo. Crítica de la sociedad presente: El exterminio por la vida», La Revista Blanca, 118, 678-681; p. 679.

86 Vives, E. (1896), «Selección al revés», Ciencia Social, 8, 234-239, pp. 236, 237 y 239. El análisis de Vives recuerda a alguna de las consideraciones del francés George Vacher de Lapouge (18541936). Vacher de Lapouge afirmaba en su libro de 1896 Les sélections sociales, que los dysgénics (los hereditariamente mediocres), se imponían progresivamente a los eugéniques (más aptos). Ello era el resultado de la acción de determinadas selecciones sociales. Citaba, al igual que Vives, la selección militar, que eliminaba a los mejores y dejaba escapar a los dysgénics. Donde ya no coincidía es en las soluciones. Lapouge proponía una selección sistemática que refundara la naturaleza humana (vid. BÉJIN, A. (1992), «Evolution du darwinisme social en France», en TORT, P. (ed.), Darwinisme et societé, París, 353-360; pp. 357-358). En cualquier caso, los escasos datos que hemos podido obtener de esta anarquista español no revelan nada de la posible influencia de Vacher de Lapouge. Más probable parece la influencia del anarquista Jean Grave. El francés habla, como Vives, de una selección «al revés» producida por las malas condiciones ambientales en que se desenvuelve la vida del trabajador y por los efectos contraproducentes del reclutamiento forzoso. GRAVE (s.fa.), Tomo I, pp. 41-42. Enrique Vives murió el 22 de Abril de 1896 en Ginebra, siendo bastante joven. Según la breve nota necrológica de Anselmo Lorenzo, de donde hemos extraído esta información, colaboró en El Productor, emigrando posteriormente a Francia. (La nota necrológica en el $\mathrm{n}^{\circ} 8$ de Ciencia Social, p. 239).
} 


\section{ÁLVARO GIRÓN}

Otros, aunque no descartan la solución revolucionaria, propondrán, mientras tanto, una procreación consciente y limitada (mediante la utilización de medios anticonceptivos), que evite la propagación de individuos degenerados. Tal es el caso del incipiente, y discutido ${ }^{87}$ núcleo neomalthusiano ${ }^{88}$, en el que la influencia del círculo de Paul Robin, la Génération Volontaire ${ }^{89}$, fue determinante. Este grupo, encabezado por Lluis Bulffi, se adhirió a la Liga de la Regeneración Humana, asociación neomalthusiana internacional, y publicó varios folletos y un periódico, Salud y Fuerza (1904-1914). El presupuesto fundamental sobre el que descansaban las ideas neomalthusianas era el de la existencia de una «oposición entre la enorme capacidad prolífica de los seres organizados y lo escaso del alimento o el poco espacio de que disponen $»^{90}$. Esto era, según ellos, claramente aplicable al ser humano. Una procreación no controlada por medios anticonceptivos llevaba a la miseria, el hambre y la

87 En el extranjero, la discusión sobre el neomalthusianismo enfrentó a Paul Robin con Kropotkin y Réclus. En España, los anarquistas de acción Mateo Morral y Pedro Vallina lo defendieron frente a Pere Esteve, Leopoldo Bonafulla y Federico Urales. ALVAREZ JUNCO (1991), p. 296; DIAZ DEL MORAL (1979), p. 181, nota 64; MAITRON (1975), pp. 344-349. El argumento de los opositores a las tendencias neomalthusianas era siempre el mismo (al margen de apreciaciones sobre el papel adecuado de la mujer y la maternidad): no existía el desequilibrio creciente entre población y subsistencias denunciado por los neomalthusianos, sino acaparamiento de la riqueza social por unos pocos. Así lo expresaba Bonafulla: «...la carencia de subsistencias, este desequilibrio que tanto preocupa a los que tratan inútilmente de rehabilitar a Malthus ante el mundo de los desheredados, estriba en el acto arbitrario de los trust comerciales, del acaparamiento de la producción y de la usurpación que de la riqueza social cometen las clases parasitarias...» BONAFULLA, L. (1905), Generación libre. (Los errores del neomalthusianismo), Barcelona, p. 6. Sobre la popularización de las doctrinas neomalthusianas, Luis Bulffi afirmaba ya en 1904: «La reciente publicación del folleto «Crimen y criminales», por Clarence S. Darrow (abogado), en el cual el grupo editor Biblioteca Amor y Maternidad Libre ha incluido «Exposición de doctrinas», nos dispensa de dar aquí larga relación de nuestros propósitos, lo cual nos complace en extremo, pues podemos asegurar (...), que más de cincuenta mil personas han leído en España dicho folleto, enterándose de los fines humanitarios que la Sección Española de la Liga de Regeneración Humana propaga (...) Además, el folleto de Sebastian Faure «El problema de la población», «Generación voluntaria» de Paul Robin y las conferencias «Prudencia sexual», «Lucha contra la Natura», «Exceso de población y miseria», «Huelga de maternidad» y «Exposición de doctrinas», celebrados en los centros obreros de la ciudad [N. del A: se refiere a Barcelona], también nos ahorran trabajo...» BULFFI, L. (1904), «Dos palabras», Salud y Fuerza, 1, 1-2; p. 1.

$88 \mathrm{El}$ neomalthusianismo tendrá mas desarrollo durante los años veinte y treinta: ALVAREZ, R. (1995), «Eugenesia y darwinismo social en el pensamiento anarquista», en HOFMANN, B., JOAN I TOUS, P. y TIETZ, M. (eds.), El anarquismo español y sus tradiciones culturales, Frankfurt y Madrid, 29-40; NASH, M. (1984), «El neomalthusianismo anarquista y los conocimientos populares sobre el control de natalidad en España» en NASH, M. (ed), Presencia y protagonismo. Aspectos de la historia de la mujer, Barcelona, 307-340; pp. 317, 319 y 320. Sobre el grupo inicial de Lluis Bulffi: ABELLÓ I GÜELL, T. (1979), El neomalthusianisme a Catalunya. LLuis Bulffi i la «Liga de Regeneración Humana», Universidad de Barcelona, tesis de licenciatura inédita.

${ }^{89}$ Sobre el caso francés vid. RonSIN, F. (1980), La grève des ventres. Propagande néo-malthusienne et baise de la natalité française (XIX-XX, siècles, Poitiers.

90 HARDY, G. (1904), «La lucha por la existencia y el neo-malthusianismo», Salud y Fuerza, 1, 2-4; p. 2. 
extenuación, que se hacía más patente en la clase obrera. El objetivo no era el de ser una masa hambrienta, de capacidad revolucionaria más que dudosa, sino el de equilibrar la relación entre población y subsistencias de tal manera que se pudiera constituir una clase obrera sana, y por tanto, poderosa..$^{91}$.

Como se puede deducir, la preocupación eugenésica del neomalthusianismo es más que evidente ${ }^{92}$. Paul Robin, por ejemplo, en un artículo publicado en El Corsario en 1896, llegaba a afirmar que «es deseable (...) un número suficiente de individuos sanos de cuerpo», pero «lo es menos tener un gran número de hijos degenerados (...) en perjuicio de la infancia de calidad mejor ${ }^{93}$. En este sentido, el conocimiento y popularización del control de la natalidad mediante medios anticonceptivos tenía, desde el punto de vista de la prevención de la extensión de la marea degenerativa, dos virtualidades principales para los neomalthusianos. En primer lugar, posibilita el equilibrar la relación entre población y subsistencias de manera no traumática, previniendo la miseria y, por tanto, la perpetuación de un medio patógeno. Y en segundo lugar, hace que aquéllos que sufren enfermedades hereditarias degenerativas tomen conciencia del peligro que constituyen para la humanidad, y puedan evitar mediante la utilización de anticonceptivos la propagación del mal. Se trata, por tanto, de evitar «hacer muchos hijos, si han de ser enfermos por la herencia física de los padres o por la miseria en que se desenvolverán. ${ }^{94}$.

Ahora bien, desde el punto de vista específico de evitar la reproducción masiva de degenerados, los anarquistas no ponen sus esperanzas, evidentemente, en la acción legal, ya que «la ley no impediría dormir en una cama a tales desgraciados.» El instrumento no puede ser otro que el convencimiento: «¿Por qué no llevarles a la convicción de que su deber es no generalizar el mal?» De hecho, la procreación en tales condiciones es un «crimen». Un crimen innecesario ya que se puede «practicar la sexualidad sin producir familia»: «¿A qué, pues, crear esclavos, anémicos o degene-

\footnotetext{
91 ¿Créese que si los revolucionarios hicieran muchos hijos harían muchos revolucionarios? Es un error. Porque los verdaderos revolucionarios son sanos de cuerpo y de cerebro...» GARCíA, V. (1912a.), «Deshaciendo errores», El Porvenir del Obrero, 314, 2-3; pp. 2-3.s

92 Mary Nash ha llamado la atención sobre un hecho que conviene destacar: lo engañoso de definir todo el movimiento eugenésico como conservador per se. El caso español muestra como una corriente principal del movimiento eugenésico puede ser no sólo situado dentro del movimiento de reforma social de principios del XX, sino en la agenda del anarquismo revolucionario: NASH, M. (1992), «Social and Nationalist Race Hygiene in Early Twentieth Century Spain», History of European Ideas, 15, $\mathrm{n}^{\circ} 14-16$, 741-748, pp. 742 y 745; NASH, M. (1995), «La reforma sexual en el anarquismo español», en HOFMANN, B., JOAN I TOUS, P. y TIETZ, M. (eds.), El anarquismo español y sus tradiciones culturales, Frankfurt y Madrid, 281-296.

93 RoBIN, P. (1896), «Regeneración. Liga para el mejoramiento de la raza humana», El Corsario, 34; pp. 3-4. El anhelo neomalthusiano era crear «una raza fuerte y sana» CHUECA, J. (1912), «Alrededor del neo-malthusianismo», Salud y Fuerza, 53, 260-261; p. 260.

94 García, V. (1912b.), «Razonemos», El Porvenir del Obrero, 318, 2-3; p. 2.
} 


\section{ÁLVARO GIRÓN}

rados? ${ }^{95}$ En cualquier caso, aún pensando que el simple convencimiento pudiera impedir la propagación masiva de las estirpes decadentes, ello no bastaba para elevar la calidad media de la especie, de tal manera que se pudiera llevar a efecto el anhelo neomalthusiano de «una raza fuerte y sana» ${ }^{96}$. Para ello había que persuadir a la población de que sólo debían reproducirse aquellos que poseían un mayor «valor biológico» ${ }^{97}$. Hay que pasar de la eugenesia negativa a la eugenesia positiva. Sin embargo, todo este esfuerzo sería baldío si en la sociedad futura no se dieran las condiciones ambientales adecuadas para la buena reproducción y posterior desarrollo de la descendencia. Si la reproducción, crianza y mejora de animales domésticos exigen el establecimiento consciente de un medio adecuado, lo mismo se puede decir del homo sapiens. Sin embargo, para un neomalthusiano como V. García, nada se ha hecho para establecer las condiciones ambientales mínimas que aseguren la buena crianza de la especie. La degeneración, a la altura de 1914, sigue constituyendo una amenaza:

«Y cosa extraña. Se estudia la manera de producir mejores frutas (...) Se procura que la yegua, la coneja, la gallina, hasta la cerda reciban los cuidados, ya en los alimentos, en los alojamientos, en la limpieza, en todo, para que mejore la especie, y sin embargo nada de esto se hace para mejorar la raza humana. Se dice al obrero: ;procrea! y no se le facilitan ni los conocimientos ni los medios para que su producto sea útil y tenga viabilidad. No se le dan los conocimientos para que las condiciones físicas sean adecuadas para una producción sana, no se le dan los medios para que pueda conservar en condiciones racionales lo que produzca. El exceso de trabajo, la escasez de alimentación, la mala calidad de la misma, la falta de higiene de talleres, fábricas, trabajos en general, alojamiento, vestuario, etc., preparan la descendencia a la desperfección, a la tuberculosis, a la degeneración»98.

\section{CONCLUSIÓN}

Para los anarquistas españoles, como para una buena parte de los socialistas europeos, la degeneración era un hecho, al menos en los años comprendidos entre finales de los años 1880 y 1914. En este sentido, por decirlo de alguna manera, jugaban en el mismo terreno que sus enemigos de clase que proponían medidas de claro tono represivo a la hora de atajar la marea degeneradora. Pero jugar en el terreno de otro, no quiere decir que no pudieran subvertir las categorías y conceptos producidos por las élites culturales

\footnotetext{
95 GARCÍA (1912b.), p. 2.

96 CHUECA, J. (1912), «Alrededor del neo-malthusianismo», Salud y Fuerza, 53, 260-261; p. 261.

97 BULFFI (1904), p. 1. Se trataba, en palabras del biólogo francés Remy Perrier, transcritas por Salud y Fuerza, de «favorecer la propagación de los individuos sanos de cuerpo y de cerebro, de los que tienen el mayor "valor social"». PERRIER, R. (1913), «La eugénica y el mejoramiento de la raza humana», Salud y Fuerza, 53, 264-265; pp. 264-265.

98 GARCÍA, V. (1914), «Neomalthusianismo», Salud y Fuerza, 61, 394-396; p. 394.
} 
de la burguesía. El establecimiento de un análisis etiológico distinto sobre las causas sociales de la degeneración se convirtió en un formidable instrumento de crítica de la sociedad presente. Es más, en la medida que se concebía que la degeneración era un proceso ubícuo e imparable, hacía más urgente la solución revolucionaria. Es también claro que los anarquistas no establecían una distinción clara entre ingeniería social e ingeniería médico-biológica. La Revolución supone un cambio en la forma de organización social, y este cambio, a su vez, permite crear las condiciones ambientales propicias que activen un proceso regenerador. Ello no sólo implica la aceptación más o menos implícita de una teoría de la herencia neolamarckiana, o la marcada preferencia por un ambientalismo extremo. Se asumió, también, una voluntad claramente antropotécnica.

Pero jugar el juego del anarquista médico de la sociedad tenía sus costes desde el punto de vista libertario. En el caso de Montseny la medicalización del vocabulario no es pura retórica. El higienismo pasa a formar parte de un discurso normalizador. Montseny aboga por un nuevo ethos basado en el concepto de salud. Un nuevo ethos que debería sustituir tanto la moralidad burguesa como las formas de sociabilidad tradicionales. Cabe preguntarse si lo mismo no es predicable para el naturismo libertario plasmado en el vegetarianismo, la lucha antialcohólica, o el propio neomalthusianismo, que floreció con gran fuerza en los años veinte y treinta. Cabe preguntarse también, si todo este discurso normalizador no formó parte del arsenal ideológico de una subcultura libertaria que, por un lado, y a pesar de su dependencia del universo de lecturas de la clase media, quería romper con la cultura dominante y, por el otro, a pesar de su evidente populismo, no encontraba fácil acomodo, dado su racionalismo utópico y cientifista $^{99}$, en aquello que se ha dado en llamar cultura popular ${ }^{100}$. Finalmente, la cuestión clave es la de si todo esto quedó en el papel. En este sentido, es más que significativa la preocupación por la higiene infantil dentro de la Escuela Moderna de Ferrer Guardia. ¿Tuvo alguna plasmación práctica el higienismo en la actividad de otras escuelas racionalistas??, ¿tuvo algún impacto el vegetarianismo o la lucha antialcohólica en la actividad de la C.N.T o la F.A.I.? Todo ello, creemos, merecería una investigación detallada.

\footnotetext{
${ }^{99} \mathrm{La}$ tensión entre el racionalismo cientifista y utópico, el culto al pueblo, y la cruda realidad de ese pueblo, irracional, tradicional, y violento, ha sido señalada por Alvarez Junco: ALVAREZ JUNCO (1986), pp. 197-208.

${ }_{100}$ Carlos Serrano señala cómo la cultura obrera marca diferencias con respecto a la cultura popular en cuestiones tan sustanciales como la estructuración del tiempo, la construcción del espacio y los símbolos. Se trata de «definir una cultura obrera que rompe a la vez con la(s) cultura(s) dominante(s) y con $\mathrm{la}(\mathrm{s})$ culturas 'populares' tradicionales, y que trata de configurar una clase obrera bien diferenciada ya de un Pueblo sin perfiles definidos.» SERRANO, C. (1989), «Cultura popular/cultura obrera en España alrededor de 1900», Historia Social, 4, 21-31; pp. 24 a 26. Sin embargo, en nuestra opinión, los anarquistas no estaban tanto por la labor de configurar una clase obrera desgajada del Pueblo, como de introducir en éste ideas, hábitos y normas de conducta inspirados en el entramado ideológico libertario, con el fin de crear una auténtica subcultura racional alejada de los patrones de conducta inspirados por la religión y los patrones tomados de la cultura y moral burguesas.
} 